\title{
The economic burden of noncommunicable diseases and mental health conditions: results for Costa Rica, Jamaica, and Peru
}

\author{
David E. Bloom, ${ }^{1}$ Simiao Chen,${ }^{1}$ and Mark E. McGovern ${ }^{2}$
}

Suggested citation Bloom DE, Chen S, McGovern ME. The economic burden of noncommunicable diseases and mental health conditions: results for Costa Rica, Jamaica, and Peru. Rev Panam Salud Publica. 2018;42:e18. https://doi.org/10.26633/RPSP.2018.18

\begin{abstract}
Objective. We extend the EPIC model of the World Health Organization (WHO) and apply it to analyze the macroeconomic impact of noncommunicable diseases (NCDs) and mental health conditions in Costa Rica, Jamaica, and Peru.

Methods. The EPIC model quantifies the impact of NCDs and mental health conditions on aggregate output solely through the effect of chronic conditions on labor supply due to mortality. In contrast, the expanded EPIC-H Plus framework also incorporates reductions in effective labor supply due to morbidity and negative effects of health expenditure on output via the diversion of productive savings and reduced capital accumulation. We apply this methodology to Costa Rica, Jamaica, and Peru and estimate gross domestic product (GDP) output lost due to four leading NCDs (cardiovascular disease, cancer, chronic respiratory disease, and diabetes) and mental health conditions in these countries from 2015 to 2030. We also estimate losses from all NCDs and mental health conditions combined.

Results. Overall, our results show total losses associated with all NCDs and mental health conditions over the period 2015-2030 of US\$ 81.96 billion (2015 US\$) for Costa Rica, US\$ 18.45 billion for Jamaica, and US\$ 477.33 billion for Peru. Moderate variation exists in the magnitude of the burdens of diseases for the three countries. In Costa Rica and Peru, respiratory disease and mental health conditions are two leading contributors to lost output, while in Jamaica, cardiovascular disease alone accounts for $20.8 \%$ of the total loss, followed by cancer. Conclusions. These results indicate that the economic impact of NCDs and mental health conditions is substantial and that interventions to reduce the prevalence of chronic conditions in countries of Latin America and the Caribbean are likely to be highly cost-beneficial.
\end{abstract}

Keywords Chronic disease; mental health; economics; aging; cost of illness; Latin America; West Indies.

A strong interplay exists between population health and economic growth (1). First, high-income populations tend to

\footnotetext{
Department of Global Health and Population, Harvard T.H. Chan School of Public Health, Boston, Massachusetts, United States of America. Send correspondence to David E. Bloom at dbloom@hsph.harvard.edu
}

have better health because they have access to more and better nutrition; safe water and sanitation; readily available

\footnotetext{
CHaRMS - Centre for Health Research at Queen's Management School, Queen's University Belfast, Belfast, Antrim, Northern Ireland.
}

and quality health care; and psychosocial resources, such as social capital and recreation facilities. Second, healthy populations develop faster economically because healthy work forces tend to be more productive and because healthy children have higher test scores, better school attendance records, and higher 
levels of educational attainment. In addition, healthy populations maintain higher rates of saving, investment, and physical capital accumulation because they expend fewer resources on health care. This process may lead to a virtuous cycle that results in further investment from abroad, increasing workers' access to more-productive machines, technology, and infrastructure. Healthy populations also tend to control their fertility, allowing them to escape the burden of youth dependency and enjoy a demographic dividend (2). Therefore, understanding patterns in population health is likely to be important, at least in part, for understanding patterns in economic growth.

Noncommunicable diseases (NCDs) and mental health conditions represent a huge disease burden and have a substantial impact on individuals, communities, and societies around the globe. In total, these conditions are responsible for roughly half of healthy life years lost as measured in disability-adjusted life years (DALYs) and roughly two-thirds of deaths worldwide $(3,4)$. In the Region of the Americas, NCDs are the leading cause of morbidity and mortality and are responsible for $80 \%$ of all deaths (5). Of particular relevance, $35 \%$ of NCD-related deaths occur prematurely (between the ages of 30 and 70), when individuals are in their most economically productive period of life (5).

As worrying as current rates of NCDs and mental health conditions are, trends in the relevant risk factors for these conditions indicate that their global burden is only likely to grow. For example, while smoking has declined in some high-income countries, the overall rates of the main modifiable risk factors for NCDs and mental health conditions-such as tobacco use, alcohol use, and obesityhave risen globally, suggesting that an increase in the rates of chronic conditions worldwide is likely to follow $(6,7)$. In addition, more sedentary occupations and unhealthy diets are becoming more common.

Demographic trends also point toward an increased future burden from NCDs and mental health conditions. In particular, the dual phenomena of urbanization and rapid population aging have significant implications. Although urbanization has many benefits in terms of efficiency and convenience, it can also facilitate dispersion of certain risk factors for NCDs, such as pollution and second-hand smoking. Given that age constitutes the main risk factor for NCDs and mental health conditions, global population aging is likely to have a major effect on overall levels of population health. While a thorough discussion of the prevalence of these conditions is beyond the scope of this paper, these details have been provided elsewhere. In addition, more information on NCDs in the Americas and the capacity of countries to respond is available in a report that was prepared by the Pan American Health Organization (PAHO) (8).

In spite of the high burden of ill health and premature death caused by NCDs and mental conditions, the availability of data capturing their economic impact is limited (9). This paper focuses on Costa Rica, Jamaica, and Peru (see Table 1 for summary statistics) and is the result of a collaboration between the Harvard T.H. Chan School of Public Health and the PAHO Department of Noncommunicable Diseases and Mental Health. That department is responsible for providing technical cooperation in the Region of the Americas to prevent and control NCDs, as well as mental conditions, and related risk factors in accordance with global and regional mandates (10).

This paper has two goals. The first is to estimate the economic impact of NCDs and mental conditions on gross domestic product (GDP). The second is to raise awareness among policymakers and other decisionmakers of these conditions' economic costs and their implications for national economic progress. Finance ministers and others in charge of resource allocation are more likely to fund programs and interventions that are evidence based, and persons seeking to influence financial decisions (such as by health ministers) can use the results presented in this paper to identify and promote the adoption of cost-effective policies, such as the "best buy" NCD interventions identified by the World Health Organization (WHO) $(11,12)$.

Although Costa Rica, Jamaica, and Peru represent different geographic areas in Latin America and the Caribbean and have different levels of economic development, they face similar demographic challenges, including recent steady increases in the proportions of their populations aged 60 and above (Figure 1). In 1980, the proportion of the population aged 60 and above was $9.3 \%$ for Jamaica, $6.1 \%$ for Costa Rica, and $5.6 \%$ for Peru. This age group now accounts for $13 \%$ of the Jamaican and Costa Rican populations and $10 \%$ of the Peruvian population. According to United Nations Population Division (UNPD) projections (https://esa.un. org/unpd/wpp/Download/Standard/ Population/), by 2050, those aged 60 and above will account for $30 \%$ of the population in Costa Rica, $28 \%$ in Jamaica, and 23\% in Peru.

Even though NCDs and mental health conditions have a significant and growing impact on the health and well-being of populations, policymakers and the public may not be aware of their full consequences. Public spending on largescale intervention programs aimed at reducing the risk factors for these diseases (such as obesity) may therefore need to be justified by comparing the expected return on investment from these programs with expected returns from other potential uses of public funds. This can only be achieved if robust estimates of the economic costs of NCDs and mental health conditions are available.

Unfortunately, assessing the economic impact of NCDs and mental health conditions is complex. Several approaches to evaluating the economic effects of chronic conditions exist, including costof-illness and value-of-a-statistical-life (VSL) methods, which aggregate estimates from individual data. The cost-ofillness method sums up direct medical

\section{TABLE 1. Summary statistics for Costa Rica, Jamaica, and Peru}

\begin{tabular}{lccc}
\hline \multicolumn{1}{c}{ Statistic } & Costa Rica & Jamaica & Peru \\
\hline Population (millions, 2014) & 4.8 & 2.7 & 31 \\
2014 gross domestic product (billions, 2005 constant US\$) & 29.4 & 11.2 & 127.7 \\
2014 gross domestic product per capita (2005 constant US\$) & 6188 & 4112 & 4124 \\
Savings rate (\%) & 17 & 15 & 21 \\
Life expectancy (years, 2013) & 79.2 & 73.4 & 74.3 \\
Percentage of persons 60+ (2015) & 12.8 & 12.8 & 10.0 \\
\hline
\end{tabular}

Source: Data from the World Bank (http://data.worldbank.org/).

${ }^{a}$ The savings rate is the average rate between 2011 and 2014. 
FIGURE 1. Percent of total population aged $60+$ in Costa Rica, Jamaica, Peru, Latin America and the Caribbean, and the world, in 1980, 2015, and 2050

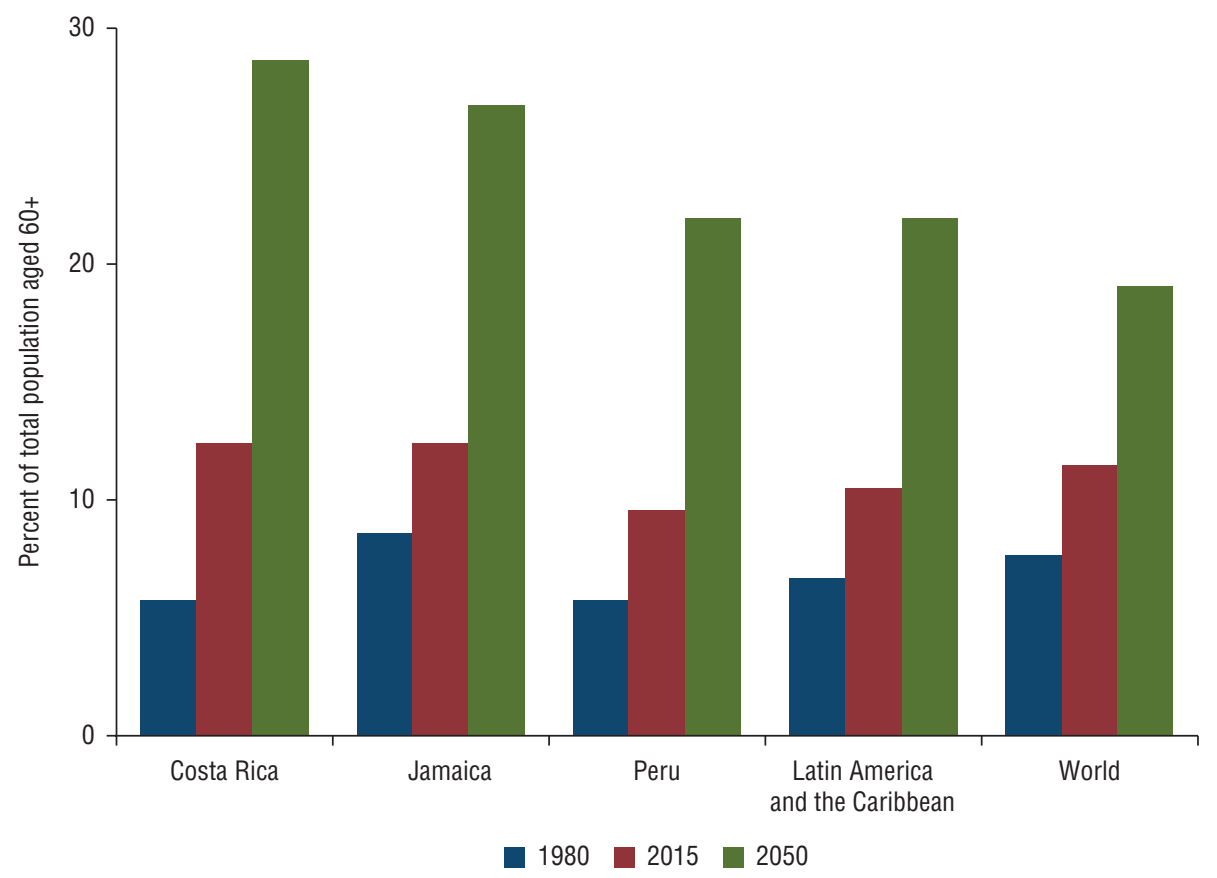

Source: Data from the United Nations Population Division.

costs, while VSL infers the monetary value of mortality reductions from willingness-to-pay studies or wage premia for risky occupations. However, these approaches do not capture the ways in which society's health status affects determinants of economic growth, such as labor markets and capital accumulation.

We expect such macro-level spillover effects to be important-a hypothesis that the literature supports (13). For example, NCDs and mental health conditions increase mortality and reduce productivity, thus reducing labor supply (14). Likewise, health care expenditures increase in response to chronic conditions, diverting savings away from productive investments and thus reducing capital accumulation.

One approach to estimating the impact of these spillover effects uses cross-country economic growth regressions $(15,16)$; however, identifying the parameters of interest can be difficult. An alternative is to build a working model of the economy, which can then be calibrated using observed data on chronic conditions and other country-specific characteristics. We can use such production function approaches to simulate different scenarios with different prevalence levels of NCDs and mental health conditions. Comparing levels of GDP and of GDP growth in various scenarios provides an economic estimate of the impact of these health conditions.

It should be acknowledged that this methodology also has limitations. For example, we do not consider the behavioral change of individuals and firms. One potential alternative is to use a general equilibrium approach. However, building such a model would be complex and could ultimately require too many restrictive assumptions to be tractable.

Despite these limitations, our methodology has two distinct benefits. First, it is an economically founded approach to estimating the cost of chronic conditions that captures the aggregate impact on society rather than on individuals. Second, it enables us to describe how the labor market and capital stock-key determinants of economic growth-respond to NCDs and mental health conditions and therefore incorporate adjustment mechanisms. In this paper, we describe how we apply this production function approach to Costa Rica, Jamaica, and Peru.

\section{METHODS}

We analyzed the economic burden of NCDs and mental health conditions using the EPIC-H Plus model. EPIC-H Plus is an updated version of two models: 1) the original WHO EPIC model and 2) our previous EPIC-H model (17).
The original WHO EPIC model estimates the impact of NCDs and mental health conditions on aggregate output by quantifying reductions in the labor supply due to mortality from chronic conditions. As in the original WHO EPIC model, GDP is modeled as a function of aggregate labor supply, the aggregate capital stock, and technological progress. Health is incorporated into this framework because chronic conditions, including NCDs and mental health conditions, affect the quantity of labor supplied in the model. A higher prevalence of NCDs and mental health conditions reduces GDP because the number of working-age individuals, and therefore the size of the labor force, decreases.

For accuracy of predictions, modeling and coding adjustments were made to the original WHO EPIC model to produce an updated model, which we refer to as EPIC-H. We subsequently developed and amended this model to produce the augmented EPIC-H Plus extension, which additionally incorporates labor supply reductions due to morbidity and the negative effects of health expenditures on output, which result from the diversion of productive savings and from reduced capital accumulation. (See Appendix B for a detailed description of data sources for the parameters used in this framework.)

The projections for national income in this framework are based on the Solow model production function, which is given by

$$
\mathrm{Y}_{\mathrm{t}}=\mathrm{A}_{\mathrm{t}} \mathrm{K}_{\mathrm{t}}^{\alpha} \mathrm{L}_{\mathrm{t}}^{1-\alpha}
$$

where economic output in each year $\left(\mathrm{Y}_{\mathrm{t}}\right)$ is modeled as a function of technological progress $\left(\mathrm{A}_{\mathrm{t}}\right)$, the capital stock $\left(\mathrm{K}_{\mathrm{t}}\right)$, and the stock of labor in the economy $\left(\mathrm{L}_{\mathrm{t}}\right)$. Alpha $(\alpha)$ describes how labor and capital combine to produce output. The production function is calibrated based on data obtained for each country, which include forecasts of population structure and the prevalence of NCDs and mental health conditions. To obtain the aggregate cost of NCDs and mental health conditions, we simulate aggregate income for each country over the period of interest in two scenarios: status quo and counterfactual.

\section{Status quo scenario}

GDP gives economic output in each year as forecasted, assuming the prevalence of NCDs and mental health 
conditions evolves as expected over the period of interest. We assume that no interventions that would reduce the mortality rate of a disease have been implemented.

\section{Counterfactual scenario}

This scenario models the complete elimination of the specified disease (i.e., the prevalence of NCDs and mental health conditions is set to zero), and this reduction in disease prevalence occurs without cost. When considered alongside the status quo scenario, the counterfactual scenario can be used to calculate the total output loss attributable to NCDs and mental health conditions, and this will be the focus of this article's analysis.

The model can also be extended to examine a proposed intervention scenario. In such an intervention scenario, GDP is calculated assuming the elimination of a designated percentage of mortality for the specified disease. For example, this could be used to evaluate an intervention that reduces the prevalence of NCDs and mental health conditions by $10 \%$. In this piece, we do not consider an intervention scenario as part of the analysis as we focus on estimating the aggregate cost of NCDs and mental health conditions.

After constructing the GDP projections for these two scenarios, the difference between GDP values in the counterfactual scenario and in the status quo scenario gives the aggregate cost of NCDs and mental health conditions. The sum of these differences in each year over the period of interest gives the total burden. Appendix A has a detailed description of the modeling methodology. Further details of model functionality and derivations are given in Bloom et al. $(17,18)$.

\section{RESULTS}

Tables A2, A3, and A4 (see Appendix C) present baseline-case estimates of the economic burden of NCDs and mental health conditions for Costa Rica, Jamaica, and Peru, during the period of 2015 to 2030. The estimates, which are given in 2015 US\$, draw on WHO mortality data and assume that the same mortality rates observed from 2005 through 2013 will hold for 2015-2030. In addition to separate economic burden estimates for each of four leading noncommunicable diseases (diabetes, cardiovascular disease (CVD), chronic respiratory disease, and cancer) and mental health conditions, estimates of the aggregate cost of all NCDs and mental health conditions are presented in each table. These aggregate estimates were obtained by scaling the figure for the five domains using the procedure based on disability-adjusted life years (DALYs) that is described by Bloom et al. $(17,18)$.

\section{The costs associated with NCDs and mental health conditions in the three countries are substantial}

According to the model, all NCDs and mental health conditions will cost Costa Rica, Jamaica, and Peru, respectively, US\$ 81.96 billion (US\$ 16143 per capita), US\$ 18.45 billion (US\$ 6306 per capita), and US\$ 477.33 billion (US\$ 15010 per capita), in 2015 US\$, from 2015 through 2030. Considering these countries' income per capita and the size of their economies, these figures represent huge costs. For Costa Rica, Jamaica, and Peru, estimates of the value of lost output are, respectively, $142 \%$, $105 \%$, and $255 \%$ of the countries' 2013 GDP. Furthermore, these estimates amount to more than 48 times Peru's total health spending in 2013, and more than 18 and 15 times that of Jamaica and Costa Rica, respectively.

\section{Moderate variation exists in the magnitude of the burdens of diseases for the three countries}

In Costa Rica, respiratory disease alone accounts for $20.1 \%$ of the total loss, followed by mental health conditions $(18.6 \%)$, and cardiovascular disease $(9.4 \%)$; diabetes accounts for only $6 \%$. Peru faces a similar situation: respiratory disease $(19.7 \%)$, mental health conditions (20.9\%), and cardiovascular disease $(8.4 \%)$ are the three leading contributors to lost output, while diabetes accounts for only $4.2 \%$. In Jamaica, the magnitude of the burden associated with specific diseases varies somewhat less than in the other two countries: CVD contributes $20.8 \%$ to the total loss, followed by cancer $(13.7 \%)$ and diabetes (13.5\%).

\section{The burden of NCDs and mental health conditions in Peru is greater than the burden in Costa Rica and Jamaica}

Figures 2, 3, and 4 compare the output losses due to NCDs and mental health

FIGURE2. Estimates of lost gross domestic product (GDP) output due to four leading noncommunicable diseases (NCDs), mental health conditions, and all NCDs and mental health conditions in Costa Rica, Jamaica, and Peru, 2015-2030

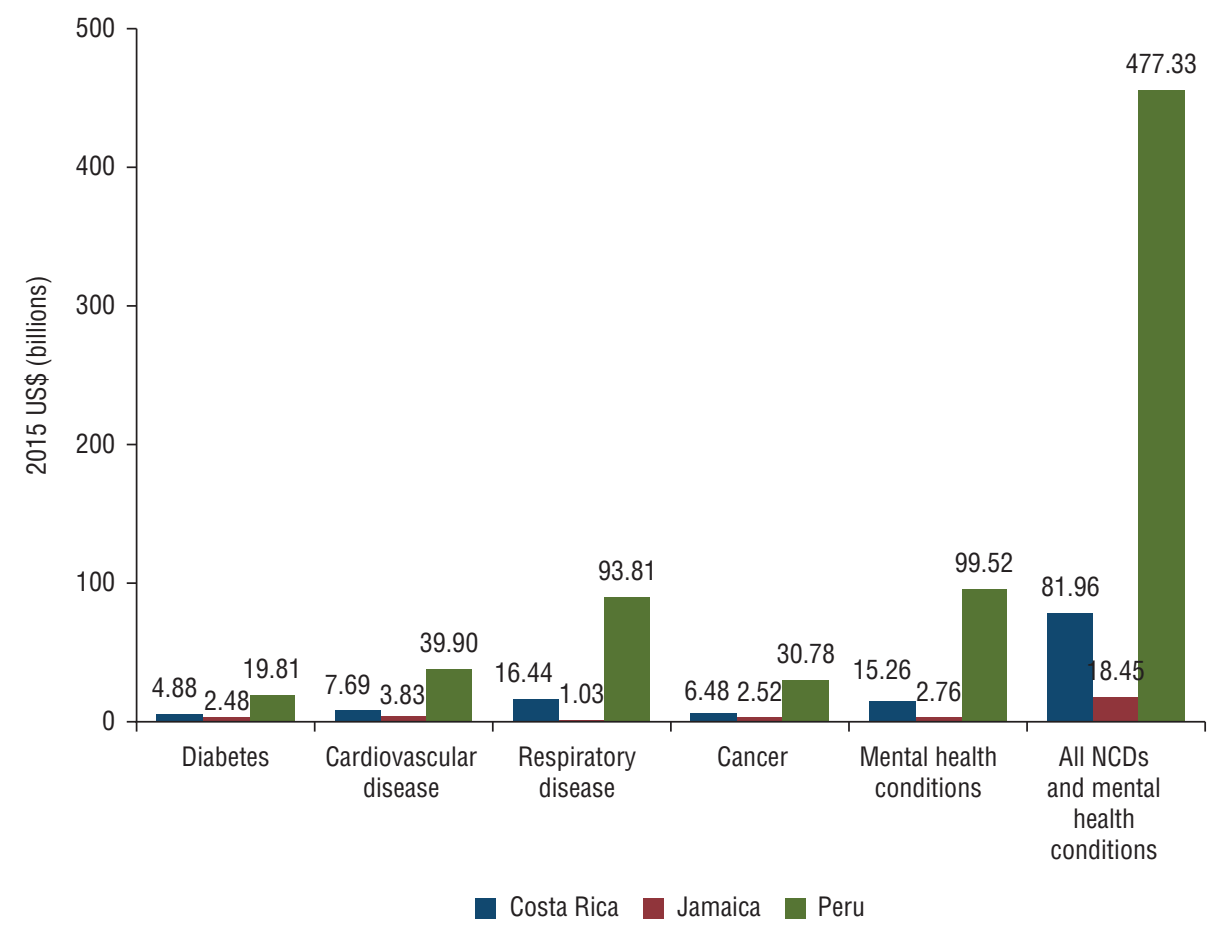

Source: Prepared by the authors based on the results of the study. 
FIGURE 3. Estimates of lost gross domestic product (GDP) per capita output due to four leading noncommunicable diseases (NCDs), mental health conditions, and all NCDs and mental health conditions in Costa Rica, Jamaica, and Peru, 2015-2030

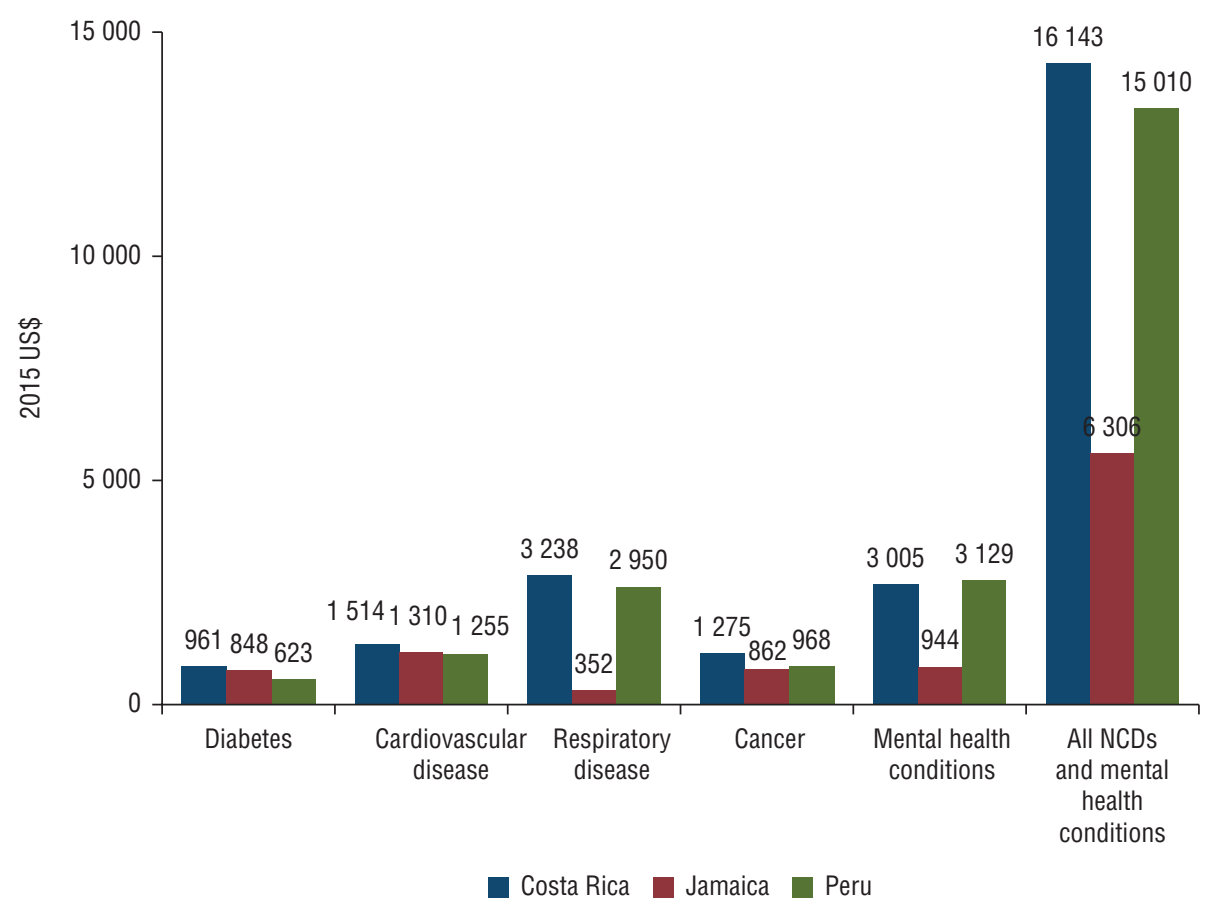

Source: Prepared by the authors based on the results of the study.

FIGURE 4. Estimates of lost gross domestic product (GDP) output due to noncommunicable diseases and mental health conditions for 2015-2030 as a percentage of 2013 GDP (in constant 2015 US\$)

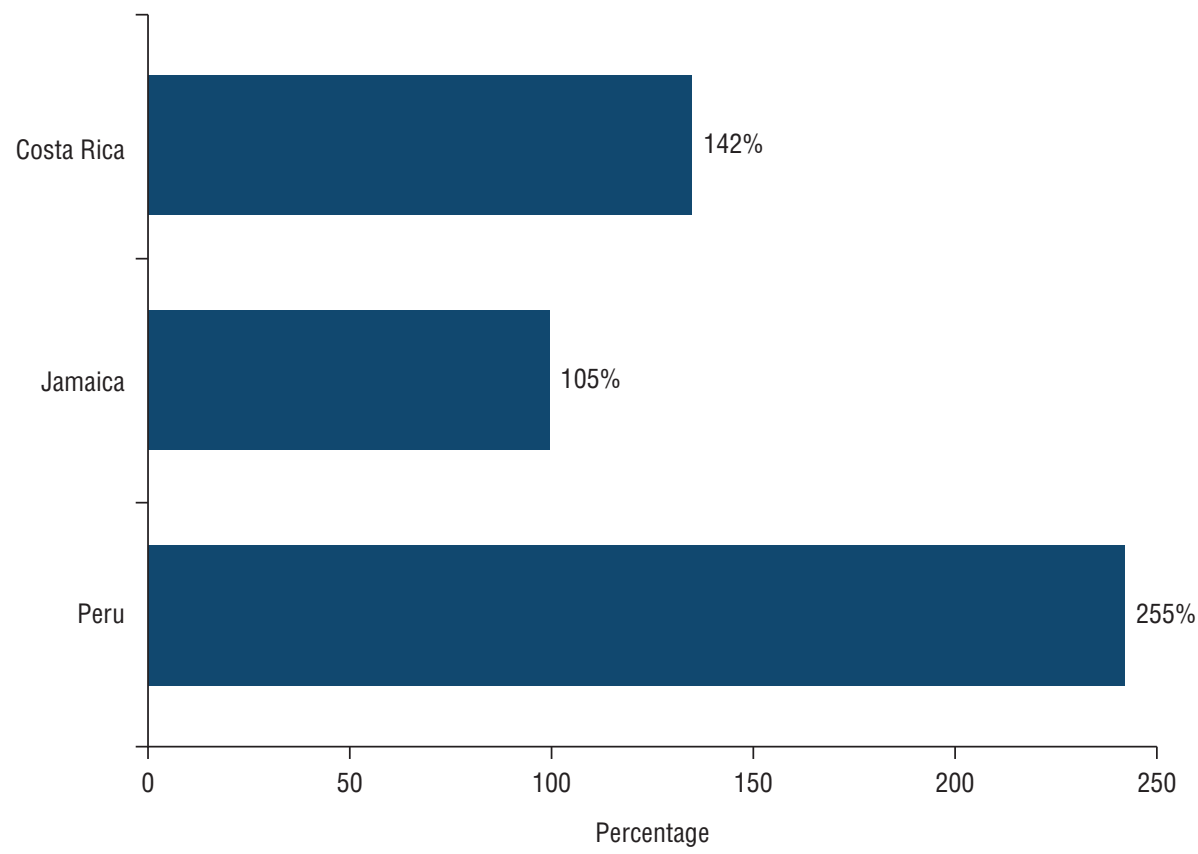

Source: Prepared by the authors based on the results of the study.

conditions in Costa Rica, Jamaica, and Peru. We present the output losses due to four leading noncommunicable diseases (cardiovascular disease, cancer, chronic respiratory disease, and diabetes), mental health conditions, and total NCDs.
Here, total NCDs (all NCDs plus mental health conditions) include cardiovascular diseases, cancer, chronic respiratory diseases, cirrhosis, digestive diseases, diabetes, urogenital diseases, blood diseases, endocrine diseases, musculoskeletal disorders and other noncommunicable diseases (including congenital anomalies, skin and subcutaneous diseases, sense organ diseases, and oral disorders), and mental health conditions. Between 2015 and 2030, Peru will suffer a larger total output loss than either Costa Rica or Jamaica (US\$ 477.33 billion versus US\$ 81.96 billion and US\$ 18.45 billion, respectively). This higher aggregate output loss may be due to Peru's larger population and initially higher level of economic output. Peru has 6 times the population of Costa Rica and almost 11 times that of Jamaica, with 4 times the GDP of Costa Rica and almost 10 times that of Jamaica.

Peru not only has the highest output loss among the countries studied at the aggregate level, but also the largest at the per capita level (US\$ 16 143). Furthermore, Peru's burden of NCDs and mental health conditions is much larger when compared with its baseline GDP. In 20152030, total losses related to NCDs and mental health conditions for Costa Rica and Jamaica, respectively, are estimated at $142 \%$ and $105 \%$ of the countries' 2013 GDPs, while the corresponding loss for Peru over the same time period is $255 \%$ of its 2013 GDP. NCDs and mental health conditions therefore pose a larger burden for Peru's economy in both absolute and relative terms. Among chronic conditions, respiratory diseases and mental health conditions are the leading causes of lost output in Peru.

The lower per capita loss in Jamaica does not necessarily mean that the burden of NCDs is small. It is mostly a result of the low GDP per capita in Jamaica at the beginning of the projection period. In addition, Jamaica's GDP is expected to grow more slowly than that of Peru and of Costa Rica (according to economic data from the World Bank); as a result, the expected per capita loss will be smaller.

We also conducted sensitivity analyses by varying data sources and assumptions (Appendix D). As it is not possible to validate our estimates directly, it is important to provide evidence that our results are robust to a variety of mortality scenarios. From the sensitivity analysis, 
we conclude that the results are similar and robust across different projection methods and data sources, and that the impact of treatment cost and morbidity is quite significant.

\section{DISCUSSION}

Our study has several implications. The first is that substantial costs are associated with NCDs and mental health conditions in these three countries of Latin America and the Caribbean. Unless the prevalence of chronic conditions can be reduced, the impact on economic growth is likely to be substantial, due to consequent reductions in effective labor supply and capital accumulation. Correspondingly, the estimates imply that cost-effective interventions targeted at reducing the prevalence of chronic conditions are likely to be cost-beneficial because of the substantial economic burden that NCDs and mental health conditions impose. Furthermore, implementing interventions designed to reduce risk factors for NCDs is likely to lead to a $25 \%$ reduction in premature mortality from NCDs by 2025 (a goal set forth by the WHO Global Action Plan for the Prevention and Control of Noncommunicable Diseases 2013-2020 (10)). Finally, these interventions could serve as a strategy to promote economic development, given the expected impact on labor supply and capital accumulation, and therefore on economic activity and output.

\section{Caveats}

The results we present here are based on a set of assumptions about how economies grow and how various inputs, including health, affect economic output. We assume that there is no excess labor available to replace the labor (or rather, effective labor) lost due to NCD-related mortality or morbidity. This assumption may be less valid in countries in which unemployment is high or in which there are large shadow economies. However, it is difficult to assess the magnitude of these effects on real output (as opposed to measured GDP). These assumptions should be borne in mind when interpreting the estimates, and this is an important topic for future research.

Our results are also based on data that were available and accessible at the time of writing. We have attempted to assess the sensitivity of these estimates to different information sources and assumptions; however, in pursuing this analysis, we found the dearth of quality data to be a major impediment to estimating the economic impact of NCDs and mental health conditions. Estimates using alternative mortality sources were found to differ, albeit not substantially in most cases. More importantly, obtaining comprehensive information on the treatment costs associated with each disease was difficult. For example, due to a lack of country-specific data, we were forced to rely on several different sources to estimate treatment costs for Costa Rica. By contrast, the availability of country-specific treatment cost data for Jamaica and Peru allowed us to provide estimates for these countries that are likely more accurate.

As another example of a data limitation, we determined that we should use DALY estimates to approximate the morbidity impact of different conditions. Alternative ways of quantifying this impact rely on survey data and have the merit of providing a direct measure of the effect of morbidity (e.g., the association between having a condition and hours worked). However, these alternative methods may require strong assumptions about how costs are measured (e.g., that the relationship is causal).

\section{REFERENCES}

1. Bloom DE, Canning D. Commentary: The Preston Curve 30 years on: still sparking fires. Int J Epidemiol. 2007 Jun;36(3):498-9; discussion 502-3.

2. Bloom DE, Canning D. The health and wealth of nations. Science. 2000 Feb 18;287 (5456):1207-9.

3. Lozano R, Wang H, Foreman KJ, Rajaratnam JK, Naghavi M, Marcus JR, et al. Progress towards Millennium Development Goals 4 and 5 on maternal and child mortality: an updated systematic analysis. The Lancet. 2011 Sep 24;378(9797):1139-65.

4. Murray CJ, Vos T, Lozano R, Naghavi M, Flaxman AD, Michaud C, et al. Disabilityadjusted life years (DALYs) for 291 diseases and injuries in 21 regions, 1990-2010: a systematic analysis for the Global Burden of Disease Study 2010. The Lancet. 2012 Dec 15;380(9859):2197-223.

5. Pan American Health Organization. Regional Mortality Information System.
Moving forward, we recommend that evaluations of the impact of NCDs and mental health conditions begin by encouraging the collection of comprehensive data to better measure the pathways linking NCDs and mental health conditions to economic outcomes. For example, expenditure surveys based on nationally representative samples of patients in each country could help to determine the actual costs associated with each disease of interest. Then, these estimates would not have to be inferred either indirectly from other sources or from cost data in other countries, as is currently necessary. Finally, although we focus on projecting future scenarios in this paper, it would be interesting to evaluate the historical impact of NCDs on economic growth in a different analysis.

Acknowledgments. We are grateful to the staff members from the Department of Noncommunicable Diseases and Mental Health of the Pan American Health Organization (Anselm Hennis, Rosa Sandoval, Brindis Ochoa, Ramon Martinez, Delia Itziar Belausteguigoitia, and Carlos Santos-Burgoa) for conducting a series of workshops in March 2015, August 2015, and May 2016. In addition, we would like to thank Daniel Cadarette for outstanding editorial assistance, as well as the journal reviewers and editors of this paper for their helpful comments.

Funding. We gratefully acknowledge funding from the Pan American Health Organization for this project.

\section{Conflicts of Interest. None declared.}

Disclaimer. Authors hold sole responsibility for the views expressed in the manuscript, which may not necessarily reflect the opinion or policy of the RPSP/ PAJPH or PAHO.
Available from: http://www.paho.org/hq/ index.php?option=com_content\&view= article\&id=10169\&Itemid $=41167$ \&lang $=e n$ Accessed on 26 August 2015.

6. Bloom D, Cafiero-Fonseca E, McGovern M, Prettner K. China and India's descent into chronic disease: killing themselves slowly. Milken Inst Rev. 2014 2nd Quarter;24-33.

7. Kearney PM, Whelton M, Reynolds K, Muntner P, Whelton PK, He J. Global burden of hypertension: analysis of worldwide 
data. The Lancet. 2005 Jan 15-21;365 (9455):217-23.

8. Pan American Health Organization. Profile of capacity and response to noncommunicable diseases and their risk factors in the Region of the Americas. Country capacity survey results, 2015. Washington, D.C.: PAHO; 2017.

9. Muka T, Imo D, Jaspers L, Colpani V, Chaker L, van der Lee SJ, et al. The global impact of non-communicable diseases on healthcare spending and national income: a systematic review. Eur J Epidemiol. 2015 Apr;30(4):251-77.

10. Pan American Health Organization. Department of Noncommunicable Diseases and Mental Health. Available from: http:/ / www.paho.org/hq/index.php?option= com_content\&view=article\&id=8929\&Itemid=852\&lang=fr_Accessed on 26 May 2015.

11. Bloom DE, Chisholm D, Llopis E, Prettner K, Stein A, Feigl A. From burden to" best buys": reducing the economic impact of non-communicable disease in low-and middle-income countries. Geneva: World Health Organization; 2011.

12. World Health Organization. Global Action Plan for the Prevention and Control of Noncommunicable Diseases 2013-2020. Available from: http://apps.who.int/iris/ bitstream/10665/94384/1/9789241506236 eng.pdf?ua=1 Accessed on 13 March 2015.

13. Well DN. Accounting for the effect of health on economic growth. Q J Econ. 2007 Aug;122(3):1265-306.

14. López-Casasnovas G, Rivera B, Currais L. Health and economic growth: findings and policy implications. Cambridge, Massachusetts: MIT Press; 2005.

15. Acemoglu D, Johnson S. Disease and development: the effect of life expectancy on economic growth. J Polit Econ. 2007 Dec; 115(6):925-85.

16. Hyclak TJ, Skeels CL, Taylor LW. The cardiovascular revolution and economic performance in the OECD countries. J Macroecon. 2016 Dec;50:114-25.

17. Bloom DE, Cafiero-Fonseca ET, McGovern ME, Prettner K, Stanciole A, Weiss J, et al. The macroeconomic impact of non-communicable diseases in China and India: estimates, projections, and comparisons. J Econ Ageing. 2014 Dec 31;4:100-11.

18. Bloom DE, Chen S, Kuhn M, McGovern M, Oxley LT, Prettner K. The economic burden of chronic diseases: estimates and projections for China, Japan, and South Korea. Hohenheim Discuss Pap Bus Econ Soc Sci. (No. 09-2017). Stuttgart: University of Hohenheim, Dean's Office of the Faculty of Business, Economics and Social Sciences; 2017.

19. Lim SS, Vos T, Flaxman AD, Danaei G, Shibuya K, Adair-Rohani H, et al. A comparative risk assessment of burden of disease and injury attributable to 67 risk factors and risk factor clusters in 21 regions, 1990-2010: a systematic analysis for the Global Burden of Disease Study 2010 Lancet. 2013 Jan 4;380(9859):2224-60.

20. Kim SG, Hahm MI, Choi KS, Seung NY, Shin HR, Park EC. The economic burden of cancer in Korea in 2002. Eur J Cancer Care (Engl). 2008 Mar;17(2):136-44.

21. Nielsen R, Johannessen A, Benediktsdottir B, Gislason T, Buist AS, Gulsvik A, et al Present and future costs of COPD in Iceland and Norway: results from the BOLD study. Eur Respir J. 2009 Oct;34(4):850-7.

22. Zhang $P$, Zhang X, Brown J, Vistisen D, Sicree R, Shaw J, et al. Global healthcare expenditure on diabetes for 2010 and 2030 . Diabetes Res Clin Pract. 2010 Mar;87(3): 293-301.

Manuscript received on 3 April 2017. Accepted for publication on 23 August 2017. 
RESUMEN

\section{La carga económica de las enfermedades no transmisibles y la enfermedad mental: resultados para Costa Rica, Jamaica y Perú}

Palabras clave
Objetivo. Ampliamos el modelo EPIC de la Organización Mundial de la Salud y lo aplicamos para analizar el impacto macroeconómico de las enfermedades no transmisibles y la enfermedad mental en Costa Rica, Jamaica y Perú.

Métodos. El modelo EPIC cuantifica el impacto de las enfermedades no transmisibles y la enfermedad mental en la producción agregada únicamente a través del efecto que las enfermedades crónicas producen sobre la oferta de trabajo debido a la mortalidad que estas causan. En cambio, el marco ampliado EPIC-H Plus también incorpora reducciones en la oferta efectiva de trabajo debido a la morbilidad y los efectos negativos del gasto en salud sobre la producción a través del desvío del ahorro productivo y la reducción de la acumulación de capital. Aplicamos esta metodología a Costa Rica, Jamaica y Perú y estimamos la pérdida en términos de producto interno bruto debida a cuatro enfermedades no transmisibles (enfermedades cardiovasculares, cáncer, enfermedad respiratoria crónica y diabetes) y a la enfermedad mental en estos países desde 2015 a 2030. También estimamos las pérdidas de todas las enfermedades no transmisibles y la enfermedad mental combinadas.

Resultados. En general, nuestros resultados muestran pérdidas totales asociadas con todas las enfermedades no transmisibles y la enfermedad mental durante el período 2015-2030 de USD 81,96 mil millones (en dólares de 2015) para Costa Rica, USD 18,45 mil millones para Jamaica y USD 477,33 mil millones para Perú. Existe una variación moderada en la magnitud de la carga de las enfermedades para los tres países. En Costa Rica y Perú, las afecciones respiratorias y la enfermedad mental son los dos factores principales que contribuyen a la pérdida de producción, mientras que en Jamaica la enfermedad cardiovascular sola representa el 20,8\% de la pérdida total, seguida por el cáncer. Conclusiones. Estos resultados indican que el impacto económico de las enfermedades no transmisibles y la enfermedad mental es considerable y que las intervenciones para reducir la prevalencia de enfermedades crónicas en América Latina y el Caribe probablemente sean muy beneficiosas en relación al costo.

Enfermedad crónica; salud mental; economía; envejecimiento; costo de enfermedad; América Latina; Indias Occidentales.

RESUMO Objetivo. Estendemos o modelo EPIC da Organização Mundial da Saúde e aplicamos para analisar o impacto macroeconômico das doenças não transmissíveis (DNT) e as condições de saúde mental na Costa Rica, Jamaica e Peru.

A carga econômica das doenças não transmissíveis e condições de saúde mental: resultados para a Costa Rica, Jamaica e Peru
Métodos. O modelo EPIC quantifica o impacto das DNT e condições de saúde mental na produção agregada unicamente através do efeito de condições crônicas na oferta de trabalho devido à mortalidade. Em contrapartida, a estrutura ampliada EPIC-H Plus também incorpora reduções na oferta de trabalho efetiva devido à morbidade e aos efeitos negativos das despesas de saúde na produção através do desvio de poupanças produtivas e redução da acumulação de capital. Aplicamos essa metodologia à Costa Rica, Jamaica e Peru e estimamos a perda de produto interno bruto devido a quatro DNT (doenças cardiovasculares, câncer, doenças respiratórias crônicas e diabetes) e condições de saúde mental nesses países de 2015 a 2030. Também estimamos as perdas de todas as DNT e condições de saúde mental combinadas.

Resultados. No geral, nossos resultados mostram perdas totais associadas a todas as DNT e condições de saúde mental no período 2015-2030 de USD 81,96 bilhões (USD de 2015) para a Costa Rica, USD 18,45 bilhões para a Jamaica e USD 477,33 bilhões para o Peru. Existe variação moderada na magnitude da carga das doenças para os três países. Na Costa Rica e no Peru, as doenças respiratórias e as condições de saúde mental são dois principais contribuintes para a perda de produção, enquanto na Jamaica, a doença cardiovascular sozinha representa $20,8 \%$ da perda total, seguida de câncer.

Conclusões. Esses resultados indicam que o impacto econômico das doenças não transmissíveis e as condições de saúde mental são substanciais e que as intervenções para reduzir a prevalência de condições crônicas em países da América Latina e do Caribe são benéficos em relação ao custo.

Palavras-chave Doença crônica; saúde mental; economia; envelhecimento; efeitos psicossociais da doença; América Latina; Índias Ocidentais. 